\title{
Computer Musical Creative Work in the Russian Initial Vocational Education System
}

\section{Trabajo creativo musical en computadora en el sistema de educación vocacional inicial ruso}

\author{
Irina B. Gorbunova*
}

Herzen State Pedagogical University of Russia, St. Petersburg, Russia. ORCID: https://orcid.org/ 0000-0003-4389-6719

\section{Nina V. Mikhutkina}

Herzen State Pedagogical University of Russia, St. Petersburg, Russia. ORCID: https://orcid.org/0000-0001-9680-9805

*Correspondence

Email: gorbunova7575@yandex.ru
Cite as:

Gorbunova, I.B., Mikhutkina, N.V. (2020). Computer

Musical Creative Work in the Russian Initial Vocational Education System. Propósitos y Representaciones, 8(2), e523. Doi: http://dx.doi.org/10.20511/pyr2020.v8n2.523 


\section{Summary}

The development of new music technologies necessitates changes in the content of music education. Musical pedagogy is faced with the task of educating creative musicians who are capable of innovative activities and inventive musical thinking. Therefore, primary music education should introduce creative learning technologies aimed at developing students' creative abilities. This article analyzes the content of students' musical and creative activities in the field of music computer technologies (MCT) illustrated by the subject "Computer Music Creative Work." The theoretical and experimental study led us to conclude that this course not only develops creative abilities but also establishes conditions for the comprehensive and harmonious development of students' personalities.

Keywords: Music Education; Music Computer Technologies (MCT); Computer Music Creative Work; Computer Arrangement; Musical Composition; Multimedia Project.

\section{Resumen}

El desarrollo de nuevas tecnologías musicales requiere cambios en el contenido de la educación musical. La pedagogía musical se enfrenta a la tarea de educar a músicos creativos que sean capaces de actividades innovadoras y pensamiento musical inventivo. Por lo tanto, la educación musical primaria debe introducir tecnologías de aprendizaje creativo destinadas a desarrollar las habilidades creativas de los estudiantes. Este artículo analiza el contenido de las actividades musicales y creativas de los estudiantes en el campo de las tecnologías informáticas de música (MCT) ilustradas por el tema "Trabajo creativo de música de computadora". El estudio teórico y experimental nos llevó a concluir que este curso no solo desarrolla habilidades creativas sino que también establece condiciones para el desarrollo integral y armonioso de las personalidades de los estudiantes.

Palabras clave: Educación Musical; Tecnologías Informáticas de la Música (MCT); Computadora de la Música Trabajo Creativo; Arreglo de Computadora; Composicion Musical; Proyecto Multimedia.

\section{Introduction}

Nowadays, the border between musicians who compose, perform, and record music has virtually disappeared. Any musician who wants to be in demand in the field of modern music should be able to work with music computer technologies (MCT) (Gorbunova, 2019; Gorbunova \& Hiner, 2019). It is no longer enough to play a musical instrument and have traditional knowledge of musical theory, classical harmony, polyphony, and instrumentation (Gorbunova \& Petrova, 2019; Alieva, Gorbunova, \& Mezentseva, 2019a). Contemporary musicians need to know about such areas of MCT as acoustics and electroacoustics, psychoacoustics, sound recording, methods of sound synthesis, sound programming languages, and so on (e.g., Gorbunova \& Chibirev, 2019; Rags, 2010; Gorbunova \& Zalivadny, 2019). Today we have a tool for the musician-researcher, performer, and creator, a tool with which it is possible to unite the whole "multilayered musical culture" [the term of Z. Lissa (1959)]. This tool is MCT - computer musical creativity - which directly studies and uses the material of the "homogeneous mediating system" of music [(the term of D. Lukach (1986)], and thereby providing the necessary level and coverage of the musical culture's manifestations. Today, a musician must have a professional knowledge of MCT and related equipment. In this regard, musical pedagogy is faced with the task of educating creative musicians capable of such innovative activity, creative solutions, and ingenuity. 


\section{Research objective and literature review}

For nearly twenty years, MCT has been actively introduced in Russia as a new type of educational and artistic activity. The Music Computer Technologies bachelor's program and the Music Computer Technologies in Education master's program were licensed and introduced into the educational process of the country's universities in 2004 and 2006, respectively. These programs were developed in the educational and methodical laboratory Music Computer Technologies at the Russian Herzen State Pedagogical University. A school of performing skills using electronic musical instruments (EMI) is currently being developed (Gorbunova, 2018a; 2018b). Classes in MCT and EMI have been introduced at musical universities, musical and musical-pedagogical educational institutions, children's art schools, children's art centers, and artistic education centers for children and youth. Numerous festivals and creative contests are held in dozens Russian cities each year, where students and teachers perform in various genres of digital and electro-acoustic music. The following contests are widely known in the country and abroad: $D E M O$, an annual All-Russian electro-acoustic music contest; Musical Palette, an international competition of creativity; and KLARINI of the 21st century, an All-Russian festival competition (with international participation). The number of participants in such competitions is steadily increasing each year, and the geography of the contestants is expanding.

However, as practice shows, teachers and the heads of educational institutions do not always understand the need for a new direction of educational activity. As a rule, teachers focused on traditional teaching methods and previously developed approaches to music education regard such innovations with disfavor. Some of these teachers define MCT and electronic music as an experimental direction, elite creativity, and an exclusive form of artistic activity. Others believe that MCT and EMI are based on "inanimate" sounds and, therefore, are knowingly flawed. New digital instrumentation for many of these teachers is associated only with pop or rock music, and they assume the instrumentation is built on primitive artistic and aesthetic imaginative concepts.

Musicians in many countries who introduce MCT and EMI face such. Scientists and educators note that, despite the effectiveness and accessibility of digital technologies in the educational process (Horita, 2014), including MCT and music technologies in music education (King, Himonides, \& Ruthmann, 2017)), teachers remain conservative in their approaches to teaching music and musical composition (Wise, 2016; Gorbunova \& Kameris, 2019). In the real musical educational process, learning programs do not correlate with the teaching of information technology (IT) (Crawford \& Southcott, 2017). Despite the fact that IT is quickly becoming an integral part of most professions, this process is much slower in the music field (Chao-Fernandez, Roman-Garcia, \& Chao-Fernandez, 2017). These issues are also discussed by innovative teachers and scholars on the pages of well-known Russian and foreign magazines (e.g. Media Music, Music and Electronics, Issues of Music Scholarship, World of Science, Culture, and Education, Computer and Music Computer Technologies anthologies, and others), reflecting on the features and trends of the modern musical educational process.

\section{Results and discussion}

\section{Music computer technologies as a new approach to classical music education}

With the development of EMI and MCT, a new chapter has begun in the history of musical art. Today, EMI offer unlimited opportunities for musicians and their creative searches and experiments. New music technologies have enriched the sound media. Musicians can record and transform sound material using digital music equipment. Various sound modules, synthesizers, and samplers employ a huge number of sounds (tones) with the ability to edit them. The musicians of today have the capability for creative research in sound-timbral programming, new organization of sound material, sound forms, and sound space, to search of new paths in musical formation, etc. 


\section{Music computer technologies in children's art schools}

MCT and EMI should not only be introduced into classical system of music education, but also raise it to a higher level that meets modern requirements. The most favorable educational environment for the development of students' creative abilities includes music computer technologies. The subject "Computer Music Creative Work" includes such creative components as the composition of computer arrangements, composition lessons, and work on multimedia projects. The following is a description of these components.

\section{Integrated method of teaching computer arrangements}

On the one hand, computer arrangements are based on the laws and principles of instrumentation and arrangement that have been forming for centuries, and on the other hand, it has its own features associated with new electronic instrumentation and its sound material. The quality of the created arrangement will depend on the correct use of the theoretical knowledge, and auditory and practical experience of the student. This is why the synthesis of theory and practice, understanding the laws of psychological and aesthetic perception of music (Alieva, Gorbunova, \& Mezentseva, 2019a; 2019b), i.e. a comprehensive method for teaching and perceiving musical information, is important in working with students in the computer musical creativity class.

During the creation of a computer arrangement, students gain not only practical, but also theoretical knowledge. The theory of arrangement includes the study of instruments and instrumentation, the history of the orchestra, styles and genres. The study of instruments in a computer arrangement class is an introduction to traditional and electronic timbres. Students study basic technical and expressive capabilities of acoustic musical instruments (range, registers, sound techniques and articulation, sound nature), get acquainted with the electronic sounds of virtual and hardware synthesizers, and analyze their acoustic properties.

The style and genre of music are crucial in solving artistic tasks during arrangement creation. A large variety of timbre palette in EMI, virtual synthesizers, and samplers makes it possible to create an arrangement for a musical piece of any style and genre. That is why the student needs to be well versed in various music styles. The composition of the orchestra also depends on the style and genre. Students get acquainted with the history of the orchestra and musical instruments, and with some orchestral styles. It is also important for students to gain knowledge in the field of instrumentation: its basic rules and techniques related to the functions of musical texture, the role of timbre in the sound formation and texture, timbre dramaturgy and methods of using means of orchestral expression.

At the arrangement lessons, the student gets acquainted with orchestral works available for children's perception. The teacher focuses on the instrumentation features of a particular musical piece, its content, style, genre, form, texture, timbre, and other means of expression. Such lessons not only expand student's perspective, but also help develop the ability to analyze the musical works in a competent and holistic manner, contribute to a deeper understanding of artistic images. To ensure the systematic acquisition of knowledge among students, it is necessary to use a variety of musical material. The students' intellectual development is one of the key challenges in the class of computer musical creativity.

The creation of arrangement can be divided into two stages - theoretical and practical. At the first stage students get acquainted with the arranging piece (create a general idea of its main artistic images) and analyze the musical material; the second stage is the creation of the arrangement itself. When analyzing the musical texture, special attention should be paid to the interconnection of individual parts and elements of the sound form, the identification of its supporting and climax points. That way the student can comprehend and embrace the musical piece in its semantic integrity and completeness. It is also important to understand what role, what expressive function each element of the music texture performs. 
Through a more detailed analysis of musical text, students note the expressive means that the composer used to reveal the figurative and emotional content of the work: the nature of the melodic line, phrasing elements, dynamic details, features of the mode, meter and rhythm, tempo and agogics, harmonic structure, etc. A holistic musical analysis helps the student to penetrate deeper into the essence of the musical piece's artistic image and to identify the means of musical expression with which the composer reveals its content.

Here are some examples of student arrangement work. The main task in creating an arrangement is to think through the timbre dramaturgy of a musical piece. The simplest timbre dramaturgy technique used by students is personification of a timbre, when a certain timbre is associated with a character (introduction of the "subject certainty" elements (the term of D. Lukach (986)) or "program music") (Figure 1, Figure 2, Figure 3).

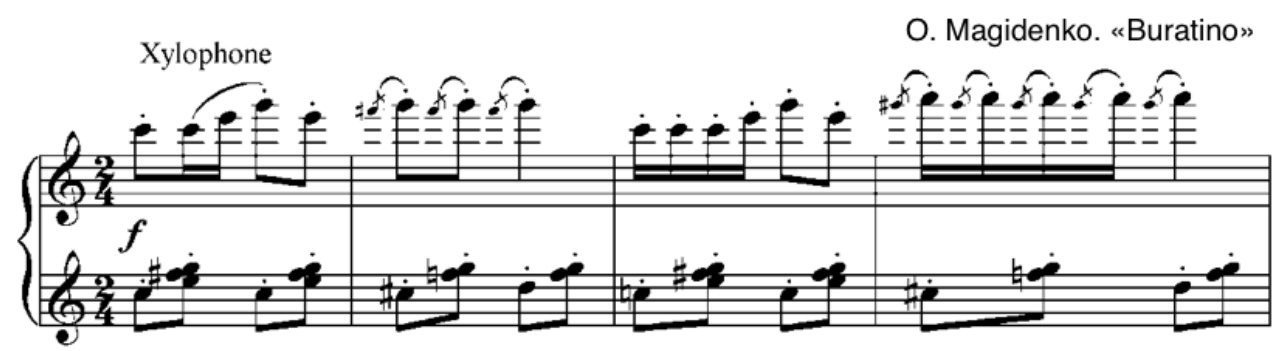

Figure 1. An example of timbre personification (xylophone)

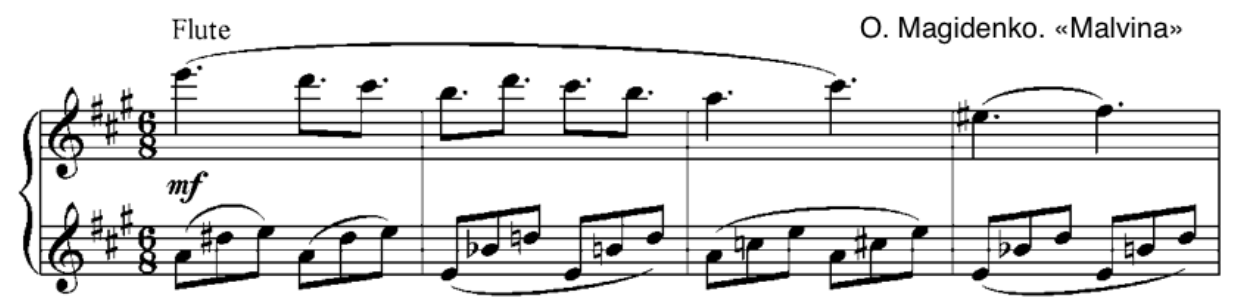

Figure 2. An example of timbre personification (flute)

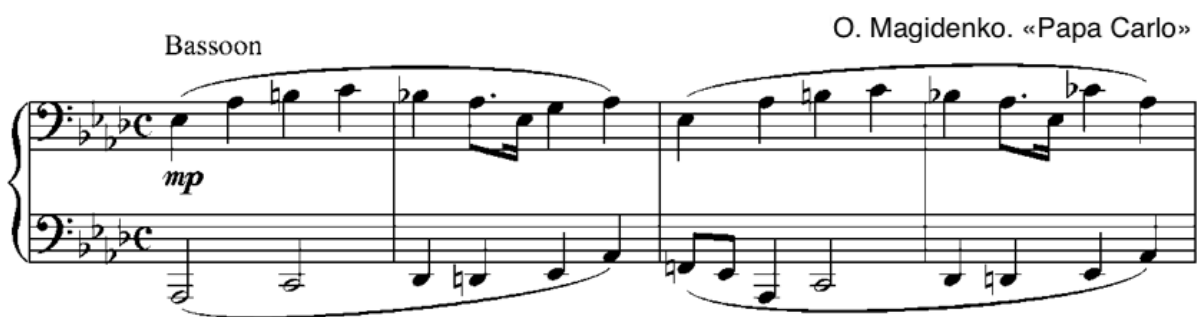

Figure 3. An example of timbre personification (bassoon)

The concept of timbre-texture functionality is associated with musical texture. Simultaneously sounding but different layers of musical texture should differ from each other in timbre or in the sound nature (Figure 4). 


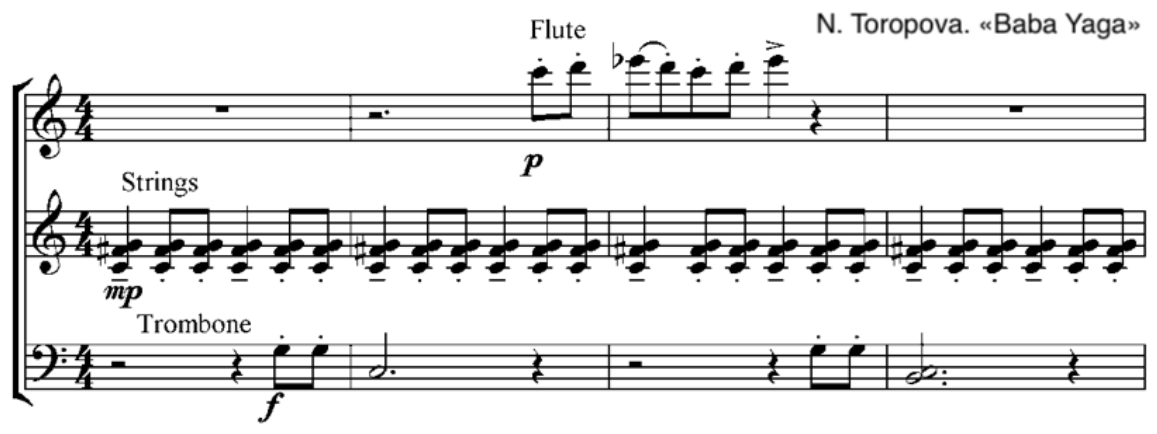

Figure 4. Different layers of musical texture

At the same time, united layers of texture should be articulated by the same or relatively equal timbre or sound nature (Figure 5).

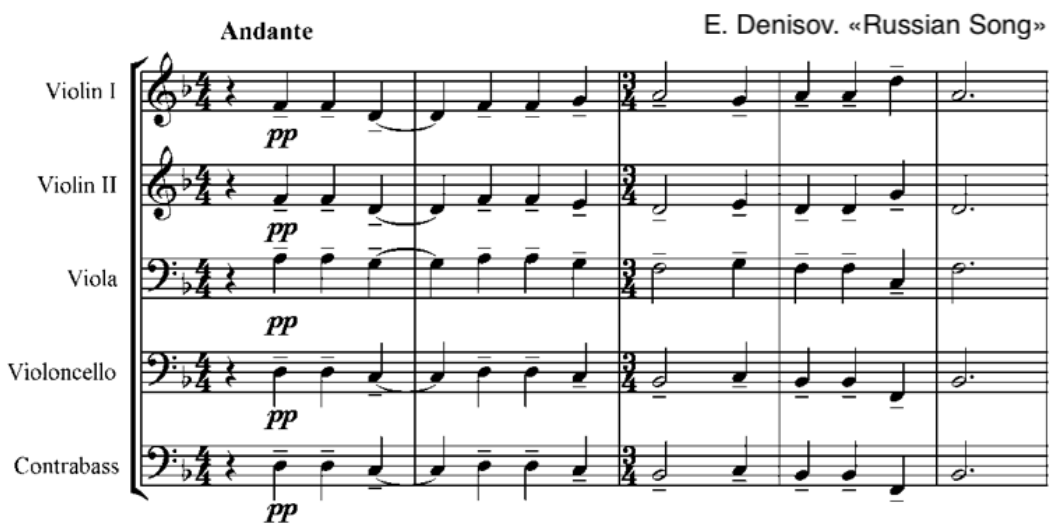

Figure 5. United texture layers

The climax is characterized by texture enrichment and dynamic amplification. This is achieved by increasing the number of instruments, adding new texture lines and harmonious voices, and expanding the orchestral range by octave voice doubling (Figure 6).

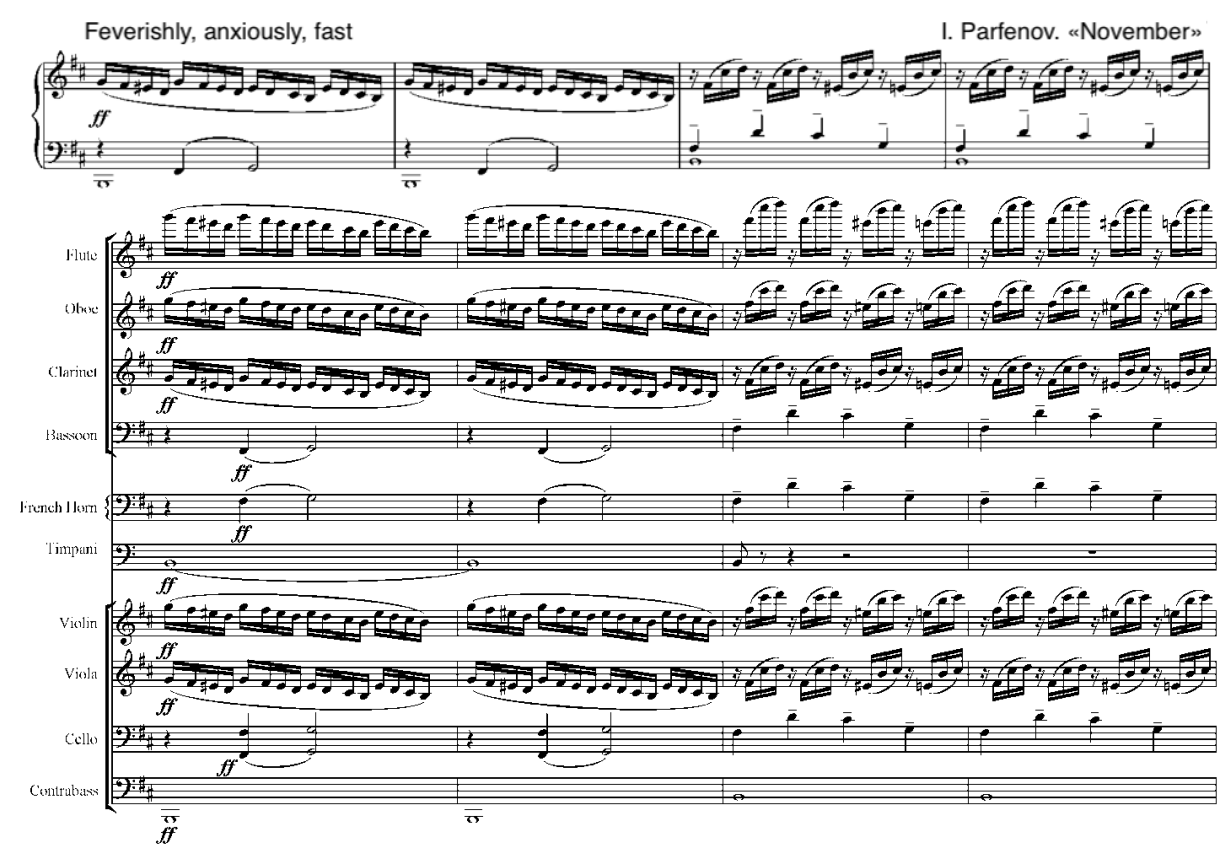

Figure 6. An example of texture enrichment and dynamic amplification 
Among others, the following timbre-orchestral techniques exist: 1. Coloring technique is associated with onomatopoeia (for example, imitation of shepherd's tunes, birds singing, etc.), the use of colorful percussion instruments, and sonorant sounds (Figure 7, Figure 8).

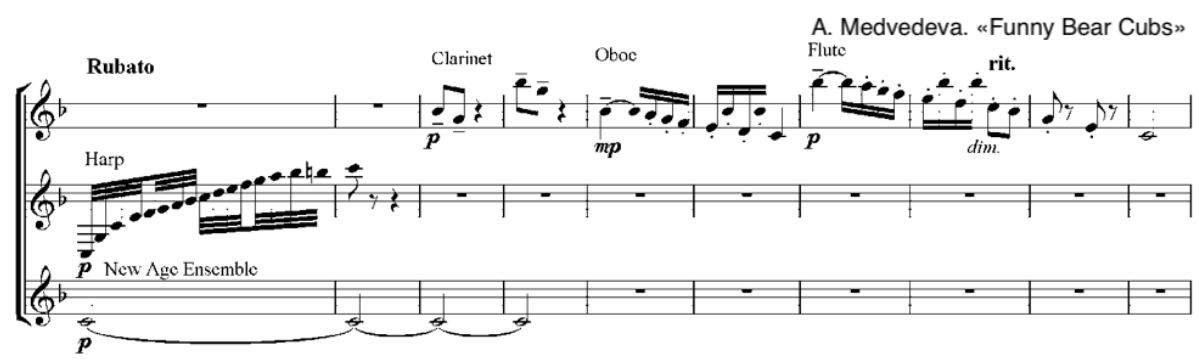

Figure 7. Coloring technique (onomatopoeia)

L. Rezetdinov. "Merry Train"

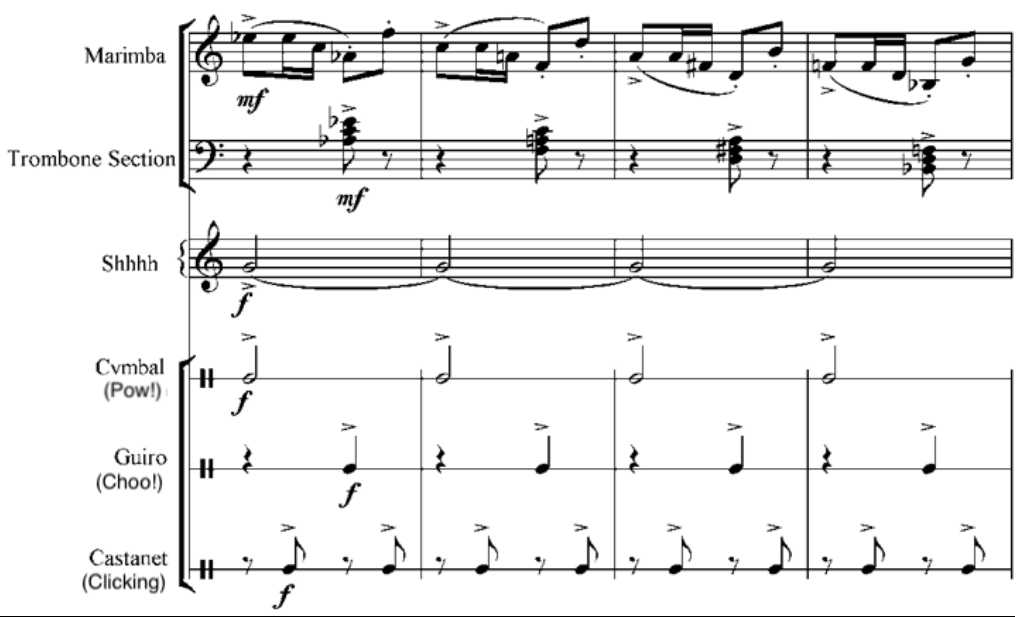

Figure 8. Coloring technique (the use of colorful percussion instruments and sonorant sounds)

2. Timbre metabola (the term of J.N. Kholopov) - switching the sound to a new timbre plane, for example, unexpected fragment switching from solo instruments to instant orchestral tutti (Figure 9). 


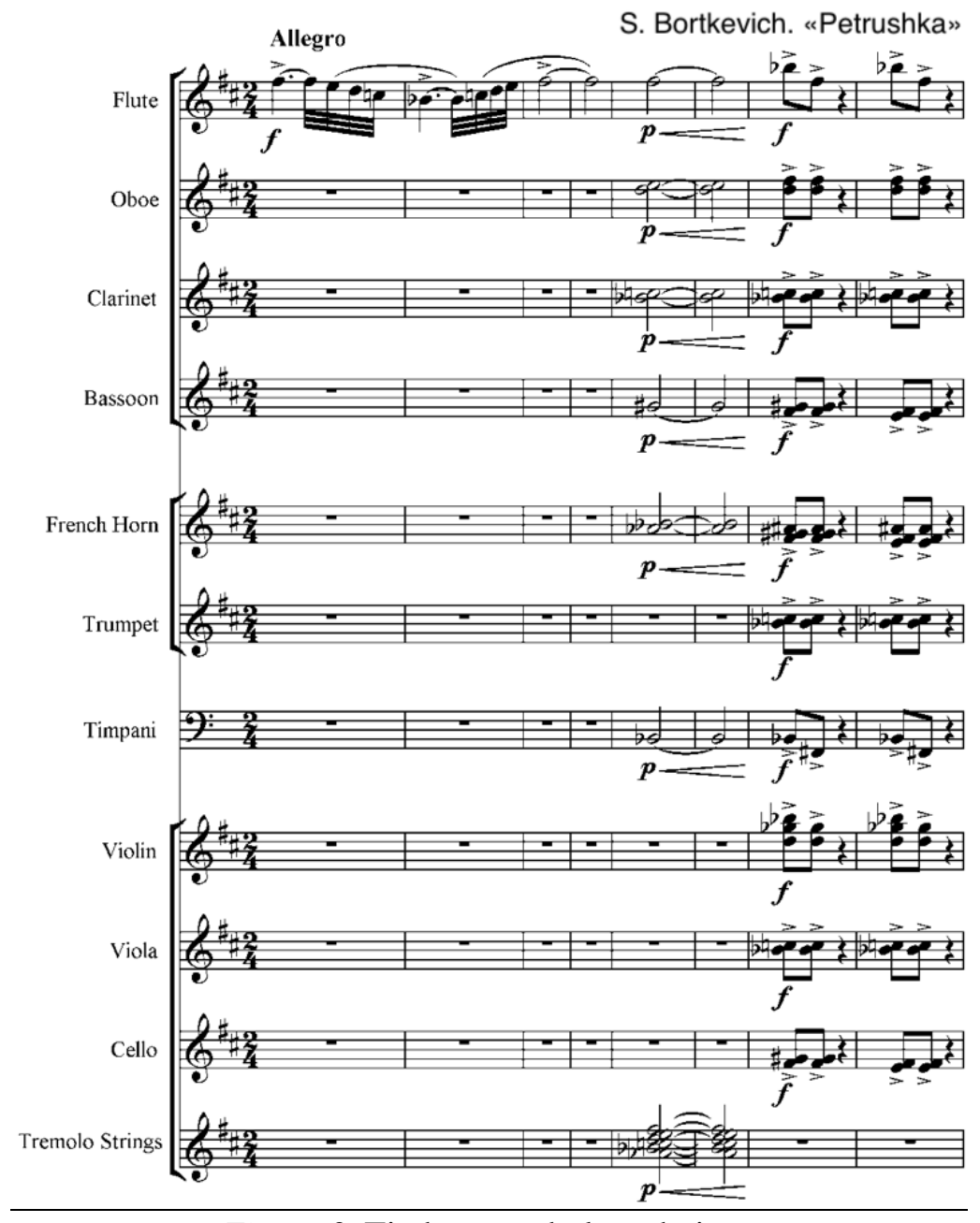

Figure 9. Timbre metabola technique

3. Kaleidoscopic nature of the thematic material. The compactness of the musical piece contributes to the constant change of timbre zones. This change results in the constant "play" of timbre colors (Figure 10). 


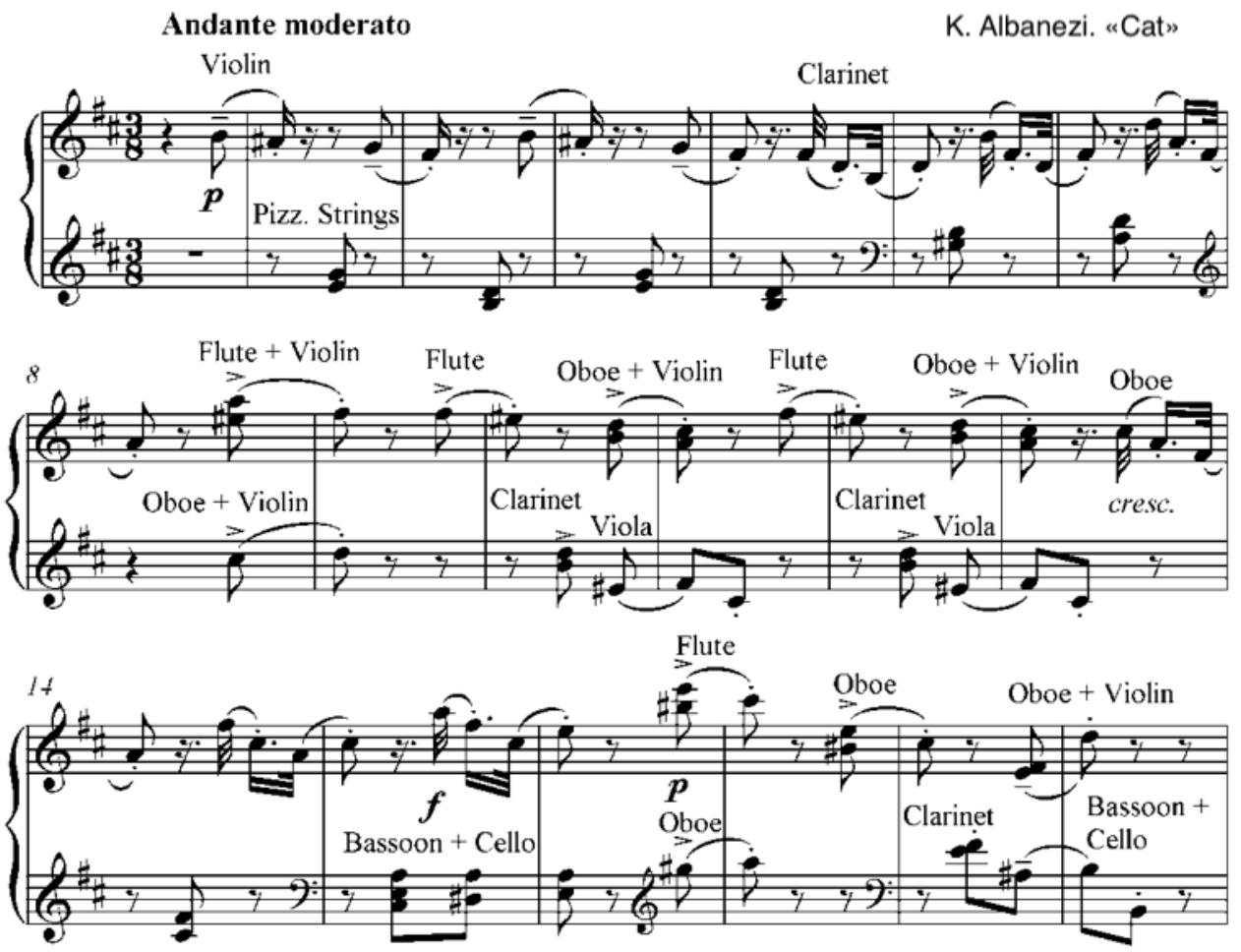

Figure 10. Kaleidoscopic nature of the thematic material

4. Imitation of folk performance (Figure 11).
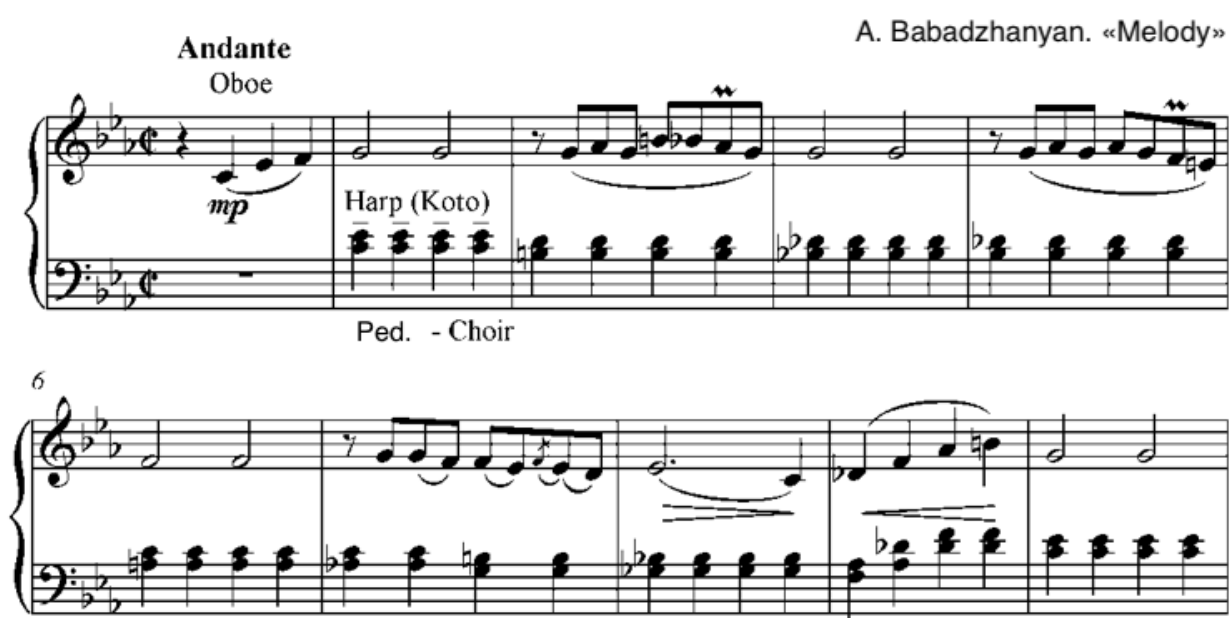

Figure 11. Imitation of folk performance

By learning all this, students gradually master the laws of various music styles, genres, and eras (Gorbunova \& Zalivadny, 2018), become acquainted with composing techniques and diverse expressive means. Understanding the constructive and artistic expressive features of music contributes to the development of students' musical thinking.

A young arranger must be able to think analytically. Teachers should encourage students to think and search, learn to determine the mood and content of music, compare and contrast, analyze and generalize, draw conclusions and prove their point. Gradually, students' musical knowledge develops into a systematic material, which they can apply on practice without any assistance. The accumulation, comprehension, and application of one's own experience help students gain independence, which gives impetus to their own conscious exploring. 
The next step in creating an arrangement is the selection and mastery of the expressive means necessary to realize the artistic content of the arrangement. The student selects suitable Virtual Studio Technology (VST) instruments and necessary timbres. Computer sound tools include a large variety of VST instruments: virtual synthesizers, samplers, sound modules, drum machines, and emulators. Sampler type instruments provide a vast amount of different sound banks: academic orchestral instruments, pop instruments, folk instruments, and various electronic timbres.

The main practical work on creating the arrangement is carried out by means of a sequencer program, including those made by Steinberg Cubase and Steinberg Nuendo. For the embodiment of an expressive musical image, the correct selection of timbres for each project channel is as important as the work on the performing components of the arrangement. The editing of MIDI messages and MIDI controllers allows students to adjust articulation, accents, phrasing, and dynamics of each project track. Because of this meticulous work, students must achieve an expressive intonation of each line, each texture element (each project track).

Next up is the sound editing of texture layers: dynamic versatility, stereophonic perspective, and correction of virtual sound volume on a frequency scale. As a result, students should achieve sound clarity and expressiveness of the entire musical texture. The correct tempo setting is also very important. To be expressive in sound, the arrangement needs some tempo deviations (agogic) that should be dictated by the artistic tasks of the arrangement. The final stage of computer arrangements is general sound processing using sound editing software (Adobe Audition, Sound Forge, WaveLab, Samplitude Studio, and others). This includes building a virtual acoustic space, general dynamic and frequency adjustment, and if necessary, addition of various effects.

Computer arrangements are not limited to using traditional tools. Students are able to experiment with synthesized timbres and sound effects, achieving new sound colors, and new sometimes unexpected timbre combinations. Summing up, it can be said that arrangement creation is a mental analytical work dependent on auditory monitoring. While creating an arrangement, working out large and small details, students must hear a variety of sound colors, the sound nature of each timbre, a subtle gradation of sound volume, a smooth transition from one sound to another, the phrasing in its small links and large constructions, hear sound perspective of texture layers, etc.

\section{Improvisation and composition}

The "Computer Music Creative Work" course is also dedicated to improvisation and composition. Musical improvisation helps students gain freedom, develop such qualities as candidness and spontaneity, find inspiration. In the process of improvisation, some kind of intonation, accord or phrase can invite a musical image, which can develop into a musical composition.

In elementary grades of school, students improvise on the subject of so-called musical pictures: images of animals, natural phenomena, mood, movement, and fairy-tale characters, etc. Improvisation promotes children's emotional self-expression and helps stir their imagination. At this stage, it is important to rely on the student's personality, steer his/her musical imagination in the right direction. Simultaneously, students get acquainted with the means of musical expressiveness: intonation, accents, dynamics, registers, tempo, and timbre. As a result, children establish emotional contact with music and form the first knowledge of musical art. As children grow, their musical abilities increase. From the first improvisations and imperfect sketches, students proceed to a more conscious and competent design of their musical thoughts.

Composition practice helps students understand the patterns of the musical language, get acquainted with its structure, types and techniques of musical forms, texture elements, and types of texture rendition. Students learn to harmonize melodies, study genre and stylistic foundations 
of music. Gradually, they master the rules and techniques of instrumentation, consolidate and systematize knowledge of musical expression means, their role and significance in creating various musical images.

Because of learning the basics of composition, students begin to understand the logic of musical development and gain practical skills in using their knowledge. They learn to express their musical thoughts and work with musical material, to look for the relationship between the concept (images) and the corresponding musical means, to correctly apply the components of expressive means in their work. Children begin to develop creative and abstract thinking; the latter is due to the dramatic evolution (scenario) of the musical piece.

Emotional content, expressiveness, originality of the musical image, and its embodiment are of the greatest importance in children's compositions. Before starting work on creating a musical composition, students select the theme; often they prefer program music. During the lesson, they discuss the dramatic aspects of a musical composition, methods of thematic development, musical form, texture, genre and stylistic features, etc. Depending on the nature of the musical image and content, students select certain means of musical expression. Children's musical compositions help to reveal their individuality and increase motivation for learning.

\section{Creation of multimedia projects and the development of students' creativity}

Another component of the course "Computer Music Creative Work" is the creation of multimedia projects, which forms a certain synthesis of musical culture, media education, and multimedia technologies. This component of the study covers the technical and aesthetic aspects of education. Multimedia projects contain various types of information (text, sound, graphic, animation, video, etc.) and are addressed to various areas of human perception. Creating a multimedia project is a complex and time-consuming task that requires multiple competencies, the use of various computer software, and different types of files (text, graphic, audio, and video).

Students prepare all kinds of information in music and graphic editing programs and then synthesize it in video editors, including those made by Pinnacle Studio, Sony Vegas Pro, Adobe Premiere Pro, and Windows Live. The process of working on a multimedia project in a video editor includes the following tasks:

- $\quad$ Script development;

- Video- and audio data acquisition and processing;

- Audio sequence creation (using prepared musical arrangement or composition, voice recording, sound effects);

- Video sequence creation (editing, addition of transitions and bonds, video effects, superimpositions and transformations, captions, etc.).

Creation of multimedia projects increases students' interest in work and cognitive activity, which motivates learners to develop their skills and gain new knowledge. Children develop the ability to independently navigate the information space and analyze information highlighting essential and important to the project things. Working with different types of information allows students to perceive all types of artistic activity based on the artistic image's integrative movement, when music, word, gesture, plastic, statics, and dynamics of the image are synthesized. Multimedia affects several sensory organs and promotes the development of perception at a high emotional level. The video sequence allows enhancing the feelings and emotions inherent in a musical work, conveying the atmosphere and mood, recreate the space of a musical composition, its rhythm and internal dynamics in visual images. The work based on the integration of various types of arts (music, video, theatrical performance) stimulates the development of rich imagination, visual thinking, creates positive mood and an atmosphere of creative uplift, interest, and enthusiasm. 


\section{Conclusion}

Because of mastering the discipline "Computer Music Creative Work," students acquire skills in working with MCT, master the main forms of musical and creative activity, get motivation for creative and cognitive activities, and develop artistic thinking and imagination, the ability to independently acquire, analyze, assimilate, and apply gained knowledge in solving artistic problems.

Based on the conducted pedagogical research, we can conclude that computer music creative work contributes to the full disclosure of the students' creative potential and enhances its nature. This provides the conditions for the comprehensive and harmonious development of children's personalities. It is necessary to actively introduce innovative forms and methods of music education, i.e. creative teaching technologies in music educational institutions. These innovations should include MCT and electronic musical equipment.

In this regard, contemporary musical education should not only train traditional musicians-performers, but also be aimed at developing students' creative abilities. A comprehensive teaching method that includes a synthesis of theory and practice, understanding the laws of psychological and aesthetic perception of music, is very important in working with students in the class of computer music creative work.

\section{References}

Alieva, I.G., Gorbunova, I.B., \& Mezentseva, S.V. (2019a). Music Computer Technologies as a Means of Broadcasting and Preserving Musical Folklore (on the Example of the Russian Far East). Issues of Music Science Music Scholarship, 1(34), 140-149.

Alieva, I.G., Gorbunova, I.B., \& Mezentseva, S.V. (2019b). Music Computer Technologies as a Worth-While Means of Folklore Studying, Preserving and Transmission. Utopia y Praxis Latinoamericana, 24(S6), 118-131.

Chao-Fernandez, R., Roman-Garcia, S., \& Chao-Fernandez, A. (2017). Analysis of the use of ICT through music interactive games as an educational strategy. 7th International Conference on Intercultural Education - Education, Health and ICT - From a Transcultural Perspective: Almeria, Spain. Procedia Social and Behavioral Sciences, 237, 576-580.

Crawford, R., \& bSouthcott, J. (2017). Curriculum stasis: the disconnect between music and technology in the Australian curriculum. Technology pedagogy and education, 26(3), 347-366.

Gorbunova, I.B. (2018a). Electronic Musical Instruments: to the Problem of Formation of Performance Mastery. 16th International Conference on Literature, Languages, Humanities \& Social Sciences (LLHSS-18). Int'l Conference Proceedings, 15-19.

Gorbunova, I.B. (2018b). New Tool for a Musician. 15th International Conference on Education, Economics, Humanities and Interdisciplinary Studies (EEHIS-18). International Conference Proceedings, 144-149.

Gorbunova, I.B. (2019). Music Computer Technologies in the Perspective of Digital Humanities, Arts, and Researches. Opcion, 35(S24), 360-375.

Gorbunova, I.B., \& Chibirev, S.V. (2019). Modeling the Process of Musical Creativity in Musical Instrument Digital Interface Format. Opcion, 35(S22), 392-409.

Gorbunova, I.B., \& Hiner, H. (2019). Music Computer Technologies and Interactive Systems of Education in Digital Age School. Proceedings of the International Conference Communicative Strategies of Information Society (CSIS 2018), pp. 124-128.

Gorbunova, I.B., \& Kameris, A. (2019). Music Computer Education Concept for Teachers: Raising the Problem. International Journal of Recent Technology and Engineering, 8(2S4), 913-918.

Gorbunova, I.B., \& Petrova, N.N. (2019). Music Computer Technologies, Supply Chain Strategy and Transformation Processes in Socio-Cultural Paradigm of Performing art: Using 
Digital Button Accordion. International Journal of Supply Chain Management, 8(6), 436445.

Gorbunova, I.B., \& Zalivadny, M.S. (2018). The Integrative Model for the Semantic Space of Music: Perspectives of Unifying Musicology and Musical Education. Music Scholarship, $4,55-64$.

Gorbunova, I.B., \& Zalivadny, M.S. (2019). Leonhard Euler's Theory of Music: Its Present-Day Significance and Influence on Certain Fields of Musical Thought. Music Scholarship, 3(36), 104-111.

Horita, T. (2014). Trend and problems of informatization at school education. Japanese Journal of Music Education Practice, 11(2), 6-13.

King, A., Himonides, E., \& Ruthmann, A. (2017). The Routledge Companion to Music, Technology, and Education. New York and London.

Lissa, Z. (1959). O wielowarstwowości kultury muzycznej. Muzyka, 1, 3-22.

Lukach, D. (1986). Singularity of Aesthetics. Vol. 2. Moscow: Progress.

Rags, J.N. (2010). Acoustic Knowledge in the Music Educational System: Essays. Ryazan: Litera $\mathrm{M}$.

Wise, S. (2016). Secondary school teachers' approaches to teaching composition using digital. British Journal of Music Education, 33(3), 283-295 